\title{
SIFAT FISIK SERBUK EFFERVESCENT RAMUAN JAMU ANTIHIPERTENSI
}

\author{
Titik Lestari \\ Poltekkes Kemenkes Surakarta Jurusan Jamu \\ Diterima : 9 Januari 2019, Disetujui : 9 Februari 2019
}

\begin{abstract}
Background: Physical Test, Effervescent Powder, Antihypertensive Herbal. Data from Basic Health Research reports that the prevalence of hypertension in Indonesia in the population aged $>18$ years is $29.8 \%$ and shows that the population of Indonesia which consumes $95.60 \%$ of herbal medicine has experienced benefits in all age groups and economic status, both in rural and urban areas but its utilization so far is still limited to self-medication and has not been done in health facilities. The scientific formula for herbal medicine for antihypertension includes Apium graveolans, Centella asiatica, Orthosiphon aristatus, Curcuma domestica, Phylantus niruri, Curcuma xanthoriza and has received a certificate from the Saintification National Herbal Medicine Commission and has been proven to be safe and efficacious. The observation authors of the use of antihypertensive herbs so far in the form of decoction preparations, it is necessary to make preparations that are practical and easy to consume and are expected with different dosage forms still have the same efficacy as lowering blood pressure, one of them in effervescent powder preparation and the need physical test for powder to find out quality standards. The aim of the study was to determine the results of the physical test of effervescent powder preparations. Method: The research method is descriptive with the research sample being effervescent powder. Results: The results showed that the results of the physical test of effervescent powder of antihypertensive herbs consisting of $\mathrm{pH}$ was 5.1, flow velocity was 6.56, stationary angle $21^{\circ}$, dispersion test was 3 minute 11 second. The moisture content of effervescent powder according to the standard is $1.5 \%$ (standard less than 5\%), while the organoleptic results of effervescent powder of antihypertensive herbs showed results in fine powder, light brown color, sour taste, distinctive smell of antihypertensive herbal ingredients and homogeneous powder. Conclusion: The conclusion showed that the results of the physical test of effervescent powder was in accordance with quality standards.
\end{abstract}

Keywords : Physical Test, Effervescent Powder, Antihypertensive Herbal

\section{PENDAHULUAN}

Hipertensi atau penyakit darah tinggi adalah suatu kondisi medis yang kronis dimana tekanan darah meningkat di atas tekanan darah yang disepakati normal dan merupakan salah satu jenis penyakit pembunuh yang paling dahsyat di dunia saat ini. Sebanyak 1 milyar orang di dunia atau 1 dari 4 orang dewasa menderita penyakit ini (Pradono, et al., 2010; Kabo P., 2011 dalam Baharuddin, 2013). Persentase penderita hipertensi saat ini paling banyak terdapat di negara berkembang, terdapat $40 \%$ negara ekonomi berkembang memiliki penderita hipertensi sedangkan negara maju hanya $35 \%$, di kawasan Asia Tenggara $36 \%$ 
orang dewasa menderita hipertensi (WHO, 2010 dalam Baharudin, 2013).

Di Indonesia, angka penderita hipertensi mencapai $32 \%$ pada tahun 2008 dengan kisaran usia di atas 25 tahun, data Direktorat Jendral Pelayanan Medik Kementerian Kesehatan RI (2010) dilaporkan bahwa hipertensi merupakan kasus ketujuh terbanyak pada pasien rawat jalan di rumah sakit di Indonesia tahun 2009. Hipertensi terjadi karena banyak faktor yang mempengaruhi dapat berlangsung cepat maupun perlahanlahan, beberapa penyebab hipertensi antara lain adalah usia, stres, obesitas, merokok, alkohol, kelainan pada ginjal dan lain-lain (Timur, 2012 dalam Baharudin, 2013). Data Riset Kesehatan Dasar (2007) melaporkan bahwa prevalensi hipertensi di Indonesia pada penduduk umur $>18$ tahun adalah $29.8 \%$. Tindakan untuk menurunkan angka kesakitan dan angka kematian akibat hipertensi dengan memberikan pengobatan hipertensi.

Pengobatan hipertensi diperlukan untuk mengontrol tekanan darah dengan menggunakan antihipertensi, selain antihipertensi yang biasa diberikan dokter (konvensional), ternyata banyak pasien yang menggunakan herbal atau kombinasi konvensional-herbal. Bangsa Indonesia telah lama mengenal dan menggunakan tanaman berkhasiat obat sebagai salah satu upaya dalam menanggulangi masalah kesehatan. Pengetahuan tentang tanaman berkhasiat obat berdasar pada pengalaman dan keterampilan yang secara turun temurun telah diwariskan dari satu generasi ke generasi selanjutnya. Hasil penelitian yang dilakukan oleh Clement et al, mengemukakan bahwa $86,8 \%$ pengguna herbal percaya bahwa herbal sama efektifnya atau lebih efektif daripada pengobatan konvensional, sedangkan penggunaan terapi kombinasi aobat konvensional dengan herbal adalah sebanyak 30\% dan kebanyakan mereka tidak menginformasikan kepada dokter (Gusmira, 2012).

Riset Kesehatan Dasar 2010 menunjukkan bahwa penduduk Indonesia yang mengkonsumsi jamu sebesar 95,60\% pernah merasakan manfaatnya pada semua kelompok umur dan status ekonomi, baik di pedesaan maupun di perkotaan tetapi pemanfaatannya selama ini masih sebatas pengobatan sendiri dan belum dilakukan di fasilitas kesehatan. Ada beberapa persyaratan agar jamu digunakan di fasilitas kesehatan, untuk memenuhi persyaratan tersebut salah satunya mengacu kepada Kementerian Kesehatan RI telah mencanangkan program unggulan Saintifikasi Jamu pada Tahun 2010 di Kabupaten Kendal kemudian diatur melalui Permenkes RI Nomor 003/Menkes/Per/2010 tentang saintifikasi jamu dalam penelitian berbasis pelayanan kesehatan. Formula saintifikasi jamu untuk antihipertensi meliputi seledri, kumis kucing, pegagan, meniran, temulawak dan kunyit. Jamu antihipertensi sudah mendapat sertifikat dari Komisi Nasional Saintifikasi Jamu serta dinyatakan terbukti aman dan berkhasiat.

Berdasarkan hasil pengamatan penulis bahwa penggunaan jamu antihipertensi selama ini dikonsumsi dalam bentuk sediaan rebusan, maka perlu dibuatkan sediaan yang praktis dan mudah untuk mengkonsumsinya dan diharapkan dengan perbedaan bentuk sediaan tetap mempunyai khasiat yang sama sebagai penurun tekanan darah, salah satunya dalam sediaan serbuk effervescent dan 
perlunya uji fisik serbuk untuk mengetahui standar mutunya.

\section{METODE PENELITIAN}

Jenis penelitian yang digunakan adalah diskriptif. Sampel dalam penelitian adalah serbuk effervescent ramuan jamu antihipertensi.

\section{HASIL PENELITIAN}

Pengembangan formula serbuk eefervescent ramuan jamu antihipertensi disajikan dalam tabel berikut ini. Adapun hasil uji sifat fisik serbuk effervescent ramuan jamu antihipertensi, seperti tercantum pada tabel 1. di bawah ini.

Tabel 1. Sifat Fisik Serbuk Effervescent Ramuan Jamu Antihipertensi

\begin{tabular}{|c|c|c|c|}
\hline \multirow[t]{2}{*}{ No } & \multirow[t]{2}{*}{ Uji Fisik } & \multicolumn{2}{|c|}{ Hasil } \\
\hline & & Hasil Uji Fisik & Standar \\
\hline 1 & $\mathrm{pH}$ & 5,1 & $4-6$ \\
\hline 2 & Kadar Air & $1,5 \%$ & $5 \%$ \\
\hline 3 & $\begin{array}{l}\text { Kecepatan } \\
\text { alir }\end{array}$ & 6,56 detik & $\begin{array}{l}\text { Tidak } \\
\text { kurang } \\
\text { dari } 10 \\
\text { gram/deti } \\
\mathrm{k}\end{array}$ \\
\hline 4 & $\begin{array}{l}\text { Sudut } \\
\text { Diam }\end{array}$ & $21^{\circ}$ & $\begin{array}{l}20^{\circ} \\
<\alpha<40^{\circ}\end{array}$ \\
\hline 5 & $\begin{array}{l}\text { Uji } \\
\text { Dispersi }\end{array}$ & 3 menit 11 detik & $<5$ menit \\
\hline 6 & $\begin{array}{l}\text { Uji } \\
\text { organolepti } \\
\mathrm{k}\end{array}$ & $\begin{array}{l}\text { Bentuk } \\
\text { serbuk halus, } \\
\text { Warna = coklat } \\
\text { muda } \\
\text { Rasa = asam } \\
\text { Bau = khas } \\
\text { ramuan jamu } \\
\text { antihipertensi } \\
\text { Keseragaman } \\
\text { tampilan } \\
\text { serbuk } \\
\text { homogen }\end{array}$ & \\
\hline
\end{tabular}

Berdasarkan tabel 1. menunjukkan bahwa hasil uji fisik serbuk effervescent jamu antihipertensi yang terdiri dari $\mathrm{pH}$, kecepatan alir, sudut diam, uji dispersi sesuai dengan standar. Kadar air serbuk effervescent sesuai standar yaitu 1,5\% (standar kurang dari 5\%), sedangkan hasil uji organoleptik serbuk effervescent jamu antihipertensi menunjukkan hasil berbentuk serbuk halus, warna coklat muda, rasa asam, bau khas ramuan jamu antihipertensi dan serbuk homogen.

\section{PEMBAHASAN}

Hasil uji fisik serbuk effervescent pada penelitian ini menunjukkan hasil kadar air 1,5\%, pH 5.1, kecepatan alir 6,56 detik, sudut diam $21^{\circ}$, uji dispersi 3 menit 11 detik, uji organoleptik warna coklat muda, bentuk serbuk halus, rasa asam, bau khas jamu antihipertensi. Kadar air pada penelitian ini sesuai dengan standar dari serbuk effervescent $5 \%$ (Kailaku et al., 2012 dalam Widiastuti, et al., 2018), kadar air merupakan parameter yang sangat penting bagi produk kering karena keberadaan air dalam suatu produk bisa menyebabkan penurunan mutu suatu produk. Kadar air yang tinggi akan meningkatkan kandungan lembab pada serbuk effervescent, kadar air dalam massa tablet effervescent merupakan hal penting karena dapat mempengaruhi terjadinya reaksi kimia dini dari effervescent yaitu ketika granul dalam kondisi lembab yang berarti memiliki kandungan air yang banyak, natrium bikarbonat akan bereaksi dengan air yang menghasilkan gas $\mathrm{CO}_{2}$ (Siregar dan Saleh, 2008 dalam Kurniasari, et al., 2014; Widiastuti, et.al., 2018) dan hasil penelitian tentang kadar air serbuk sesuai dengan penelitian Rizal, 2014 yang menunjukkan bahwa hasil rerata kadar air pada ekstrak kering dengan konsentrasi dekstrin didapatkan hasil yang berbeda, pada konsentrasi dekstrin 5\% didapatkan kadar air sebesar $5.09 \%$, sedangkan pada konsentrasi 
dekstrin $10 \%$ sebesar $3.80 \%$ dan pada konsentrasi $15 \%$ didapatkan kadar air sebesar2,64\%. Hasil penelitian juga sesuai dengan Kurniasari, et al., 2014 yang mendapatkan hasil kadar air granul didapatkan rata-rata antara 1,70-2,90\%. Penelitian Kristiani, 2013 menunjukkan hasil kadar air dari minuman serbuk effervescent serai yang diperoleh dari tiaptiap perlakuan antara 7,48-9,36\% dengan kadar air paling rendah F1. Kadar air yang diperoleh cukup tinggi bila dibandingkan dengan SNI 01-4320-1996 (Syarat Mutu Minuman Tradisional) dengan persyaratan minimal 0,3 dan memberikan pengaruh beda nyata pada minuman serbuk serai. Hal ini dapat dipengaruhi oleh berbagai sifat bahan tambahan pangan yang digunakan dalam penelitian.

Pengukuran tingkat keasaman atau kebasaan oleh suatu larutan diukur menggunakan skala $\mathrm{pH} 0-14$, hasil uji fisik $\mathrm{pH}$ pada penelitian ini menunjukkan nilai 5,1 . Hasil penelitian sesuai dengan penelitian Widiastuti, 2018 bahwa $\mathrm{pH}$ tertinggi diperoleh pada perlakukan F5 dengan komposisi asam sitrat $8 \%$, asam tartrat $4 \%$ dan natrium bikarbonat 38\%. Hasil yang diperoleh berbeda-beda tiap perlakuan F1-F5 (5,05 sampai 6,95). Perlakuan F1 memiliki pH terendah atau paling asam dari perlakuan lainnya, hal ini dikarenakan tingginya kandungan asam sitrat dan asam tartrat yang ditambahkan, juga rendahnya kandungan natrium bikarbonat yang ditambahkan. Sementara itu, perlakuan F5 memiliki pH tertinggi atau $\mathrm{pH}$ mendekati netral karena penambahan natrium bikarbonat yang semakin tinggi dan sedikitnya kandungan asam sitrat dan asam tartrat. Hasil penenlitian ini juga sesuai dengan penelitian Kurniasari, 2014 yang menunjukkan hasil pengujian derajad keasaman yang didapatkan dari kesembilan formula mempunyai kisaran 4,25-5,45; variasi $\mathrm{pH}$ pada setiap formula disebabkan oleh proses granulasi yang dilakukan secara manual sehingga pencampuran bahan tidaak homogen dan termasuk dalam produk pangan berasam sedang yaitu $\mathrm{pH}$ 4,5-3,7 sehingga aman bagi lambung. Data hasil uji $\mathrm{pH}$ pada penelitian 5,1 termasuk dalam kategori bahan pangan berasam lemah, menurut Fardiaz, 1989 dalam Kurniasari, 2014 berdasarkan derajad keasaman bahan pangan digolongkan menjadi 3 kelompok yaitu bahan pangan berasam lemah dengan kisaran $\mathrm{pH}$ 5,3-4,5; bahan pangan berasam sedang dengan kisaran $\mathrm{pH}$ 4,53,7; dan bahan pangan berasam kuat dengan nilai $\mathrm{pH}$ dibawah 3,7. Hasil penelitian ini juga tidak sesuai dengan penelitian Kristiani, 2013 hasil analisis $\mathrm{pH}$ pada minuman serbuk effervescent serai memberikan hasil yang berbeda nyata dari F1-F3 yaitu kisaran $\mathrm{pH}$ anata 6,06-5,13. Kisaran $\mathrm{pH}$ tersebut merupakan $\mathrm{pH}$ asam, karena semakin rendah nilai $\mathrm{pH}$ menunjukkan tingginya keasaman dari suatu produk. Terbentuknya $\mathrm{CO}_{2}$ pada saat reaksi effervescent dalam air yang sebagian akan larut membentuk asam karbonat akan mengurangi ion $\mathrm{H}^{+}$dalam larutan sehingga menyebabkan keasaman pada larutan dan berakibat nilai $\mathrm{pH}$ akan rendah (Kusnadhi, 2003 dalam Kristiani, 2013).

Pengukuran waktu alir dilakukan untuk mengetahui kecepatan alir granul pabila granul memiliki kecepatan alir lebih dari 10 detik maka dapat mempengaruhi keseragaman bobot granul (Elfiyani, et al., 2014 dalam Widiastuti, et al., 2018). Kecepatan alir serbuk effervescent dalam penelitian adalah 6,56 detik, hal ini menunjukkan bahwa 
kecepatan alir kurang dari 10 detik. Hal ini sesuai dengan penelitian Widiastuti, et al., 2018 bahwa serbuk effervescent dengan variasi konsentrai F1 sampai dengan F5 menunjukkan rerata waktu alir 5,$63 ; 3,87 ; 3,23 ; 4,20$ dan 6,17 detik. Rerata waktu alir menunjukkan hasil yang berbeda disebabkan karena pengaruh dari penambahan asam sitrat dan asam tartrat. Asam sitrat yang bersifat higroskopis mampu meningkatkan kadar air dalam serbuk sehingga menyebabkan serbuk mudah lembab. Konsentrasi asam tartrat yang berbeda mempengaruhi waktu alir. Asam tartrat dengan konsentrasi yang lebih tinggi akan mempunyai densitas yang besar sehingga bobot molekul akan lebih besar pula dan memudahkan serbuk untuk mengalir, waktu alir dipengaruhi oleh bentuk, ukuran, porositas, densitas dan gaya gesek antar partikel granul (Anshory, et al., 2007, Anam, 2013 dalam Widiastuti, et al., 2018). Hasil penelitian ini juga sesuai dengan penelitian Lestari, et al (2014) tentang Formulasi dan Evaluasi Fisik Granul Effervescent Sari Buah Naga (Hylocereus undatus), yang menunjukkan hasil bahwa dari keempat formula yang dibuat semua menunjukkan sifat alir yang baik dimana sudutnya masih masuk pada syarat yang ditentukan, serta pada pengujian waktu alir kekempat formula memberikan waktu alir yang hampir sama.

Sudut diam dilakukan untuk mengetahui baik atau tidaknya kecepatan alir granul. Hasil penelitian sudut diam menunjukkan $21^{\circ}$, hasil ini sesuai standar sudut diam serbuk effervescent. Hasil $\left(20^{\circ}<\alpha<40^{\circ}\right)$. Hasil penelitian sesuai dengan hasil penenlitian Kurniasari, et al. 2014 kesembilan formula memiliki sudut diam antara 28,82-39,48 ${ }^{\circ}$ yang menunjukkan bahwa granul termasuk kedalam mudah mengalir (Aulton, 1988 dalam Kurniasari, 2014). Faktor yang mempengaruhi sudut diam adalah semakin tinggi timbunan serbuk, maka semakin besar sudut diam/sudut istirahat sehingga semakin besar gaya adhesi-kohesi sehingga daya alir semakin buruk. Hal ini menunjukkan dengan adanya sudut diam dalam penelitian ini yang kecil maka waktu alir juga sesuai standar kurang dari 10 detik.

Uji organoleptik meliputi warna, aroma, rasa dan bentuk dari suatu sediaan, dalam penelitian ini warna serbuk effervescent adalah berwarna coklat, aroma khas jamu antihipertensi, rasa asam adanya hasil pengukuran $\mathrm{pH} 5,1$ menunjukkan kategori asam lemah, bentuk serbuk halus dan homogen. Menurut Martindale, 1989 dalam Kusnadhi 2003 menyatakan bahwa natrium bikarbonat, asam sitrat dan asam tartrat bersifat higroskopis dan memiliki tingkat kelarutan yang cukup tinggi. Sifatnya yang higroskopis sangat mudah untuk mengikat air di udara, maka penyimpanan perlu diperhatikan (Kristiani, 2013).

\section{KESIMPULAN DAN SARAN}

Kesimpulannya Sifat fisik serbuk effervescent ramuan jamu antihipertensi yang meliputi uji organoleptik, $\mathrm{pH}$, kadar air, sudut diam, kecepatan alir, dan waktu dispersi sesuai dengan standar. Saran kepada peneliti lain untuk melakukan penelitian lanjutan dengan menggunakan metode ekstrak yang lainnya.

\section{DAFTAR RUJUKAN}

Baharuddin, Kabo P., Suwandi, D., 2013. Perbandingan Effektivitas dan Efek Samping Obat Antihipertensi 
terhadap Penurunan Tekanan Darah Pasien.

Gusmira, S., 2012. Evaluasi Penggunaan Antihipertensi Konvensional dan Kombinasi Konvensional-Bahan Alam Pada Pasien Hipertensi di Puskesmas Wilayah Depok. Makara. Vol 16 (2) : 77-83.

Kristiani, B.R., 2013. Kualitas Minuman Serbuk Effervescent Serai (Cymbopogon nardus (L.) Rendle) dengan Variasi Konsentrasi Asam Sitrat dan Na-Bikarbonat. Yogyakarta. Program Studi Biologi. Universitas Atma Jaya.

Kurniasih, S.D., et al., 2014. Penentuan Aktivitas Antioksidan Rumput Laut Ulva sp. Dari Pantai KrakalYogyakarta. Journal of marine Research. Vol 3(4):617-626.

Lestari, PM., Radjab, NS., Octaviani, A., 2014. Formulasi dan Evaluasi Fisik Granul Effervescent Sari Buah Naga (Hypocereus undatus). Farmasains. Vol 2(4) : 182-185.

Rizal, D., Putri, W.D.R., 2014. Pembuatan Serbuk Effervescent Miana (Coleus (L) benth) : Kajian Konsentrasi Dekstrin dan Asam sitrat terhadap Karakteristik Serbuk Effervescent. Jurnal pangan dan Agroindustri. Vol 2(4) :210-219.

Syamsul, ES., Supomo, 2014. Formulasi Serbuk Effervescent Ekstrak Air Umbi Bawang Tiwai (Eleuterine Palmifolia ) Sebagai Minuman Kesehatan. Trad. Med. J., Vol. 19(3): 113-117

Widiastuti, RA., Tamrin, Asyik, N., 2018. Pengaruh Variasi Konsentrasu Asam Sitrat, Asan tartrat, dan Natrium Bikarbonat Terhadap Sifat Fisik, Kimia dan
Organoleptik Produk Minuman Instan Effervescent Bubuk Kakao (Theobroma cacao L.). J Sains dan Teknologi Pangan. Vol 3(3) : 1341-1355.

Wijaya, A.T., 2017. Hipertensi. Diakses darihttp://www.kerjanya.net/faq/10 773-hipertensi. html. 26/02/2018 